Trinity University

Digital Commons @ Trinity

Psychology Faculty Research

Psychology Department

1999

\title{
Research Methods in Cognition and Emotion
}

W G. Parrott

Paula T. Hertel

Trinity University, phertel@trinity.edu

Follow this and additional works at: https://digitalcommons.trinity.edu/psych_faculty

Part of the Psychology Commons

Publication Details

Handbook of Cognition and Emotion

\section{Repository Citation}

Parrott, W. G., \& Hertel, P. (1999). Research methods in cognition and emotion. In T. Dalgleish \& M. J. Power (Eds.), Handbook of cognition and emotion (pp. 61-81). Wiley.

This Contribution to Book is brought to you for free and open access by the Psychology Department at Digital Commons @ Trinity. It has been accepted for inclusion in Psychology Faculty Research by an authorized administrator of Digital Commons @ Trinity. For more information, please contact jcostanz@trinity.edu. 


\section{Chapter 4}

\section{Research Methods in Cognition and Emotion}

W. Gerrod Parrott

Georgetown University, Washington, DC, USA

and

Paula Hertel

Trinity University, San Antonio, TX, USA

\section{INTRODUCTION}

In this chapter we critically survey research methods used in the field of cognition and emotion. Research on cognition and emotion addresses a great variety of topics, which include the ways in which emotional states influence cognitive processes, the role of cognition in producing emotion, and folk categories and knowledge of emotion. So great is this variety that a brief chapter cannot address all the research methods that have contributed to the expansion of knowledge that has occurred in recent years; there are too many methods, and many are relevant only to particular specialized topics. Specialized research methods are discussed throughout this volume in the chapters devoted to the relevant topics. In this chapter we restrict our attention to methodological issues that span the field of cognition and emotion, yet are in some way unique to it. Not surprisingly, these are the issues and methods that have to do with emotion itself.

What is common to most research on cognition and emotion is the inclusion of emotional states as an element of the research design. Emotions are sometimes treated as independent (or quasi-independent) variables, as categories or dimensions that may be associated with changes in other variables. At other times, emotions are treated as dependent variables, as states whose quality or intensity may be influenced by other variables. There is a noteworthy parallel between research designs in which emotional state is an independent variable and those in 
which emotional state is a dependent variable. Research on emotions' effects on cognition uses mood or emotion as an independent variable, and an important methodological issue for such research is how to produce different emotional states that then can be compared in their effects. A typical solution is to employ a "mood induction"-showing a film or playing music, for example-so that participants can be randomly assigned to one of the emotional states of interest. In such research, the techniques of inducing emotional states are prerequisite to studying the effects of the emotional states. Compare this research design to one that investigates the circumstances that give rise to moods or emotions: here, the independent variable will be a manipulation of factors hypothesized to influence the quality or intensity of emotional states, and the dependent variable will be the emotional state itself. In such research the independent variable will be analogous to what in the previous design was the mood induction, and the dependent variable will be analogous to what in the previous design was the independent variable. When the quality and intensity of moods and emotion are measured, they have the status of "manipulation checks" if emotional states are an independent variable and of "dependent variables" if emotional states are a dependent variable.

Because of these parallels we organize this chapter into three sections: the first on the ways that emotional states are incorporated into research, whether as independent, quasi-independent, or dependent variables; the second on the manner in which emotion is measured, whether as manipulation check or as dependent variable; and the third on general issues regarding the design of research on cognition and emotion.

\section{WAYS THAT EMOTIONAL STATES ARE INCORPORATED INTO RESEARCH}

When emotional states define one of the independent variables, the research methods associated with them play a foundational role in the research, for they define (and sometimes literally produce) the phenomena to be studied. The selection of method is therefore crucial and yet often complex, for all methods carry disadvantages as well as advantages, and successful research often requires matching these to the research question as well as demonstrating convergence of several methods. When emotional states serve as one of the dependent variables, the focus of the research is usually on the causes or concomitants of the emotion, and the manner in which emotion is assessed can powerfully affect the types of conclusions that can be drawn.

There are four basic approaches to incorporating emotional states into research. First, the states may be induced by circumstances imposed by the researcher. Alternatively, naturally occurring circumstances (outside the researcher's control) may be taken advantage of for purposes of creating temporary emotional reactions. Third, longer-lasting emotional tendencies, such as 
emotional traits or affective disorders, may be employed as quasi-independent variables or as correlational variables to study cognition and emotion. Finally, one may consider a fourth approach to consist of methods that do not attempt to induce emotional states at all: participants may be asked only to imagine a certain emotional state, to read a vignette describing one, or to recall an occasion in which they experienced a certain emotional state. Each of these methods has its place in research on emotion and cognition, as well as its limitations, so each is discussed separately below.

\section{Manipulations that Induce Emotional States}

\section{Induced Emotional States as an Independent Variable}

Because researchers want to be able to infer a causal relationship between emotional states and performance on cognitive tasks, they have developed a variety of experimental techniques for inducing emotional or neutral states in randomly assigned participants. The success of each technique is then assessed by one or more measures. Techniques have been developed for eliciting a variety of emotional states under randomized laboratory conditions. These include such emotions as anger, anxiety, pride, envy, guilt, and embarrassment; however, by far the most attention has been devoted to moods rather than to emotions, and most of that to elation and sadness.

The earliest of the modern techniques is the Velten Mood Induction Procedure (Velten, 1968). Participants are randomly assigned to read a series of statements that gradually increase in the degree of affectivity or, in the neutral induction, describe mundane facts. A multitude of other techniques exists, including hypnosis (Bower, 1981; Friswell \& McConkey, 1989), autobiographical recall (Goodwin \& Williams, 1982), guided imagery (Miller et al., 1987), and experiences of success or failure (Isen et al., 1978); participants may be exposed to films (Gross \& Levenson, 1995; Philippot, 1993), to photographs (Fox, 1996), to odors (Ehrlichman \& Halpern, 1988), or to music (Clark, 1983); there are mood inductions that use posed emotional facial expressions (Laird et al., 1991), symmetric facial contractions (Larsen, Kasimatis \& Frey, 1992), and unilateral facial contractions (Schiff, Esses \& Lamon, 1992). Some researchers have developed hybrid inductions, including two or more techniques at once, which may produce greater intensity (Mayer, Allen \& Beauregard, 1995).

Researchers face a variety of issues when selecting a mood induction. One concern is the duration of the resulting mood, because moods can be relatively brief under some conditions (Chartier \& Ranieri, 1989). Another concern is the intensity of the resulting mood, which can affect the generalizability of the findings if it is either greater or lesser than the corresponding everyday phenomena of interest (see e.g. Ellis \& Ashbrook, 1988).

In selecting a method it is important to avoid producing confounds with the 
dependent measures-one certainly should not induce mood using autobiographical recall when studying the effect of mood on autobiographical recall, and more subtle confounds must be avoided as well. It is crucial to keep in mind that either the induction itself or the measure of its effectiveness may invite participants to perform cognitive tasks in particular ways. For example, Velten's statements included some that suggest impaired cognitive processes, so Seibert \& Ellis (1991) modified his technique by removing such statements and by introducing a new procedure of asking participants to free associate to each statement. The latter modification may have introduced a different source of demand, however, because the subsequent cognitive procedures in their research assessed mind wandering (Hertel, 1997). Other induction procedures can establish other forms of demand, depending on their cover stories. Musical procedures, for example, might establish changes in arousal that are subsequently perceived as alterations of emotional state only when participants are asked to make mood ratings. In this regard, the manipulation check becomes part of the manipulation, and its use as a verification of mood misses the mark of independence. More generally, a mood manipulation can increase the likelihood that certain subsequent materials will be better attended to, or that certain thoughts and memories will come to mind, merely on the basis of within-session cueing, regardless of effects on mood. Such changes could be an intentional strategy adopted by participants trying to act as if they were sad or happy (Perrig \& Perrig, 1988) or they could also be due to recruitment of mood-related material by a conceptual context that has been established. Whatever the mechanism, researchers need to be wary of such confounds between mood inductions and dependent variables.

Two issues that figure importantly in such considerations are whether research participants are to be informed that mood alteration is the goal of the procedure, and whether participants are to be asked to try to alter their own moods. Some mood inductions quite explicitly inform the participants that the topic of the research involves the effects of emotional states and that an emotional state will likely be induced; some inductions also explicitly request that the participants cooperate in this effort by trying to achieve and sustain the desired emotional state. Other mood inductions attempt to alter participants' emotional states more surreptitiously with success/failure, odor, background music, autobiographical recall, or narratives, and often disguise the induction with a cover story (such as the device of the "prior unrelated experiment"). Whether enlisting the participants' cooperation in altering mood makes the induction more effective seems to depend on the type of induction: it appears to help with autobiographical recall (Lanterman \& Otto, 1996) but to be unnecessary for music (Kenealy, 1988).

Most important is the implication of these issues for demand characteristics and thus for interpretation of the results. There are many types of demand, and their consequences for internal and external validity depend on the controllability of the cognitive process being studied and on the relevance of selfregulation and generalizability to the topic of the research. There is some 
evidence that cover stories are generally effective and that participants' responses are probably not faked in any straightforward sense (Berkowitz \& Tróccoli, 1986), but more subtle demand characteristics remain a concern. For example, one particular form of demand characteristic has been termed the subject compliance hypothesis of mood-congruent memory (Blaney, 1986). According to this hypothesis, mood inductions that explicitly encourage subjects' efforts to sustain their induced moods may cause participants to direct their thinking in ways that produce mood-congruent biases; the observed effects would therefore be due to participants' efforts at maintaining their moods, rather than to the moods themselves. The hypothesis has credibility given that, in the absence of any mood induction, instructions to cooperate in establishing the target mood can have effects similar to those produced by music or the Velten technique (Slyker \& McNally, 1991) and that participants who are told to act as if they are in a particular mood show mood congruent recall (Perrig \& Perrig, 1988). In fact, when cooperation instructions were omitted from a musical mood induction, Parrott \& Sabini (1990) found evidence of mood incongruence in autobiographical recall. In a different study, however, Parrott (1991) instructed participants to cease their mood maintenance, and their performance nevertheless demonstrated a mood-congruent effect in autobiographical recall. It may be that the subject compliance hypothesis holds true while participants seek to maintain their moods, but that once the moods are well established they resist self-regulation for a time without continued efforts at mood maintenance. Thus, when the procedures allow, mood maintenance or role playing might underlie effects from experimental inductions, whereas attempts at mood regulation more likely typify participants in naturally dysphoric states (Hertel \& Rude, 1991; Parrott, 1993).

Because the effects of mood inductions can include cognitive and demand effects, it is advisable to include control conditions to test for their effects (or to employ an induction that has already been so tested). A good example is the series of experiments conducted by Snyder \& White (1982), who introduced control conditions to differentiate the cognitive and demand effects of the Velten induction from its emotional effects. In addition to the standard Velten procedure, they included conditions in which participants only anticipated an elated or depressed induction (Experiment 2) as well as conditions in which participants received an ineffective mood induction (Experiment 3), and they showed that only participants receiving the actual Velten mood induction showed cognitive bias.

Given the difficulties in eliminating demand effects, it is generally safer to use one of the more surreptitious mood inductions. However, it should be noted that participants may glean the purpose of even these inductions. The simple presence of numerous emotion-related questions asked before and after the procedure may make the point of the procedure rather obvious. This problem can sometimes be solved by placing the manipulation check after the cognitive task (Parrott \& Sabini, 1990), but this solution may not always work because the effects of inductions are not always evident after the distraction and delay of 
the experimental task. It is good practice, whenever participants' awareness of the experimental hypotheses may be an issue, to question participants about this issue during a post-experimental debriefing session.

In reaching some tentative conclusion about the utility of experimental inductions, we make the following suggestions. First, induction procedures should be chosen on the basis of their freedom from demand characteristics for the specific topic being researched. If the topic of research concerns how people normally react to emotional states, then surreptitious mood inductions are preferred; more obvious inductions may be acceptable if the implications of the research do not include people's reactions to and regulation of their emotional states. Second, it should be acknowledged that the effects of the induction might result from changes unrelated to mood per se; solutions to this problem include running control conditions to check for effects of demand or contextual priming, as well as looking for convergence of findings in multiple experiments that use a variety of inductions and tasks. Third, most research using mood inductions should evaluate the influence of demand characteristics by debriefing participants, asking for their beliefs and suspicions about the experimental hypotheses while also realizing that some sources of demand can occur outside of awareness.

\section{Induced Emotional States as a Dependent Variable}

Induced emotional states serve as a dependent variable when the purpose of research is to discover the causes of emotion or the emotional consequences of an independent variable. Just as random assignment of participants to mood inductions provides the best evidence of the effects of emotional states, so too does randomized manipulation of emotional precursors provide the best evidence of emotions' causes. The power of this type of research stems from the use of actual emotional states to assess the effects of factors that are experimentally manipulated. Experimental manipulation of the degree and legitimacy of frustration, for example, has yielded insight into the causes of anger (Kulik \& Brown, 1979), and systematic variation of the outcome and self-relevance of bogus personality tests has yielded insight into the effects of upward social comparisons on envy (Salovey \& Rodin, 1984). Research on the emotional consequences of artistic and scientific problem solving (Feist, 1994), or of rumination and distraction (Nolen-Hoeksema \& Morrow, 1993) are further examples of this type of research design.

This approach is subject to several limitations, however. Foremost are the ethics of subjecting participants to conditions producing intense emotions, or of deceiving them about the presence of such conditions. It is unethical to randomly assign participants to conditions eliciting profound emotional states such as grief or depression, and other research methods must be used to study these emotions. Pragmatic limitations also exist: some emotional elicitors are difficult to produce even when it is ethical to do so. One difficulty stems from the brevity of experiments, which makes it difficult to simulate the goals and 
interpersonal relationships that typically influence emotions. One solution is to personalize the manipulation, tailoring it to the individual participant's selfconcepts and concerns so that long-term concerns may be addressed even within short-term experiments. Another difficulty stems from the subtlety of appraisals needing to be tested as compared with the relative clumsiness of experimental manipulations. Here the only solution rests with researchers' cleverness and skill, as exemplified in the research cited in the previous paragraph. The advantages of employing induced emotional states as the dependent variable make it ideal for research on antecedents of emotional states, including appraisals, but for other topics the difficulties we have described have led researchers to opt for other methods.

\section{Naturally Occurring Temporary Emotional Reactions}

A variety of techniques take advantage of emotions and temporary moods that occur naturally in the context of the participant's daily life; these states can serve either as quasi-independent variables or as dependent variables. One motivation for adopting such techniques is to avoid threats to internal validity caused by the experimental context serving as a framework for the participants' behavior. And even if one grants the internal validity of a laboratory method, a researcher nevertheless may wish to adopt more naturalistic methods to ensure the ecological validity and generalizability of the findings. Furthermore, some effects are not captured well in the laboratory: long emotional episodes, long-lasting effects, and emotion's consequences for ongoing social relationships are generally not available in laboratory research. Some aspects of emotional states simply must be studied naturalistically: The epidemiology of emotions, the rates of occurrence of emotions, or the actual features of emotion that appear in everyday life are all examples.

The principal drawback of this approach is that it cannot ensure that participants are randomly assigned to conditions. Research designs using naturally occurring states are quasi-experimental or correlational. If issues of causality are to be addressed, it is therefore necessary to try to test plausible alternative explanations of the findings by examining the data (Cook \& Campbell, 1979). The extra difficulty of establishing causality is often worth the trouble, because research on cognition and emotion in field settings permits use of situations that have strong personal significance and are enmeshed in the context of real life.

Because of the decrease in experimental control, the distinction between emotional states as independent and dependent variable is less sharp; still, one can contrast research that emphasizes the consequences of emotional states with research that emphasizes the precursors of emotional states. Examples of the former would be research in which participants are approached as they leave a movie theater, still in an emotional state, and asked to make social judgments (Forgas \& Moylan, 1987); or research on flashbulb memory, in which emotional reactions to a public event are considered as possible factors in later memory 
reports (Conway et al., 1994). An example of research focusing on the precursors of emotional states might be research on the effect of expectations and attributions on emotion, in which participants are queried shortly after receiving an important grade in a course (Van Overwalle, Mervielde \& De Schuyter, 1995).

Another advantage of naturalistic methods is that they enable researchers to take advantage of exceptional circumstances to test emotions that are more profound than can be produced in the laboratory and are unusual even in everyday life. For example, the withdrawal of a political candidate from an election allowed a test of laboratory findings about appraisal (Levine, 1996), and the occurrence of an earthquake after the administration of a questionnaire to a large sample permitted a test of the effects of certain cognitive styles on depression and distress (Nolen-Hoeksema \& Morrow, 1991)

A number of research methods have been developed specifically for working with naturally produced emotional states. Some researchers supply participants with questionnaires or structured diaries in which data can be recorded as soon as possible after emotional states occur in everyday life (Oatley \& Duncan, 1994; Planalp, DeFrancisco \& Rutherford, 1996; Rimé et al., 1991). Other researchers, interested in sampling time rather than sampling emotions, have supplied participants with alarm-equipped wrist watches or radio-activated beepers to signal the time for data gathering.

\section{Emotional Traits and Affective Disorders}

Some research on cognition and emotion investigates longer-lasting emotional tendencies, such as emotional traits or affective disorders, rather than (or in addition to) momentary emotional states. These longer-lasting dispositions enter research designs in several ways. Sometimes researchers are interested in these stable emotional dispositions themselves, comparing the performance on a cognitive task of participants who score high and low on some individual difference measure such as trait anxiety (Dalgleish, 1995). At other times researchers are interested in distinguishing the effects of these stable emotional dispositions from those of temporary emotional states, using an individual difference measure of the former in combination with a mood induction of the latter (Byrne \& Eysenck, 1995; Fox, 1996).

Because traits or disorders are pre-existing at the time of research in all but longitudinal research, studies most often focus on the concomitants or consequences of these longer-lasting tendencies. Yet there is nothing in principle to prevent researchers from investigating the precursors of traits or disorders; researchers simply must adopt the same quasi-experimental and correlational methods that are necessary for studying naturally occurring temporary emotional states, with similar difficulties in establishing causality. But, whereas nonexperimental approaches are optional for research on temporary emotional states, they are virtually the only option for research on affective disorders and 
emotional traits. There is now a large literature on the precursors of emotional disorders, which employs correlational, quasi-experimental and longitudinal research methods (see the chapters in this volume on affective disorders). It is less common to see research on the precursors of emotional traits, but similar methods may be used. A good example would be recent research investigating how adult emotional traits are related to early attachment experiences and parental rearing styles (Magai, Distel \& Liker, 1995).

The use of clinically derived categories of affective disorders (e.g. generalized anxiety disorders, phobias, major depression or dysthymia) and categories based on self-report measures of enduring mood states and traits (e.g. test anxiety or depressed states) introduces a host of methodological issues, but we must limit our discussion to only two: generalizability and specificity. Other relevant issues, including the validity of diagnostic instruments and methods for establishing the etiology of affective disorders, are beyond the scope of this chapter.

Generalizing from self-reports on inventories such as the Beck Depression Inventory (BDI; Beck et al., 1961) to emotionally disordered samples cannot be justified. In this regard, the literature contains several useful sets of guidelines for research with student samples (e.g. Deardorff \& Funabiki, 1985; Kendall et al., 1987). In particular, Kendall et al. recommended multiple method assessment, including a clinical interview if the researcher intends to use the term "depressed" as a nosologic category. Without multiple measures, the use of cutoff scores, such as 10 or greater on the BDI, should be accompanied by references to "dysphoria", a term that denotes non-specific negative affectivity. Yet, in spite of these and other guidelines for the use of the BDI, published reports of experiments on "depression" and cognition often still include one-session, onemethod assessments and refer to their participants as "depressed" if their scores exceed a low cut-off (see Haaga \& Solomon, 1993).

Even less well-justified is the tendency to generalize from induced moods to natural long-term states and dispositions, yet many researchers use terms like "depressed" to refer to the participants who have undergone an induction procedure (e.g. Ellis \& Ashbrook, 1988; Snyder \& White, 1982). Such usage seems imprecise without systematic comparisons of experimental inductions and naturally occurring states (see Gotlib, Roberts \& Gilboa, 1996). Consider that in one of few such comparisons, Hertel \& Rude (1991) found a lack of correspondence in free recall between experimentally induced participants and dysphoric participants; the different patterns were interpreted in terms of differing motivation and demand in the two samples.

A second issue concerns the specificity of the findings to particular disorders, compared to their applicability to psychological distress more generally. For example, it has long been acknowledged that scores on the BDI are moderately correlated with scores on anxiety inventories and other measures of negative states (Clark \& Watson, 1991; Gotlib, 1984); both college students and patient samples show such correlations (Vrendenburg, Flett \& Krames, 1993). Indeed, anxiety may characterize depressed states (Alloy et al., 1990). 
Therefore, the issue of specificity-to "depressed" mood apart from anxious mood-extends to studies with participants diagnosed with depressive disorders (e.g. major depression or dysthymia) via a structured clinical interview. Consider, for example, that memory impairments are not unique to depressed samples but characterize other psychopathological syndromes (Burt, Zembar \& Niederehe, 1995).

Although comorbidity is an ongoing concern in the clinical literature, building a literature on cognitive correlates of dysphoria or depression does not necessarily entail claims that the phenomena are unique to those states or syndromes. Clearly, when the research hypothesis concerns the cognitive components of a particular theory of depression (e.g. Beck's theory), we must contrast findings from a carefully diagnosed sample of depressed participants to those obtained from other diagnosed groups. However, if the research is guided by theories in cognitive psychology, it should be sufficient to show that performance differs according to the presence or absence of dysphoria or depression, and other studies might examine similar patterns in anxiety. When cognitionemotion interactions take the same form across diagnostic groups or mood categories, this outcome is no less interesting to the researcher than if the pattern had been constrained to one category alone. As the field has matured in recent years, interest in the interaction of emotion and cognition is motivated not merely by the goal to distinguish among nosological categories (Ingram, 1984) but also by the goal to examine the adequacy of mainstream cognitive theories in accommodating individual differences in emotional states (Williams et al., 1988).

In summary, we recommend that researchers who examine the correlates of any classification scheme: (a) carefully describe the research as correlative and not indirectly imply causal status to the category; (b) distinguish between essentially self-reported and diagnostic categories fully throughout their discourse; (c) resist the temptation to generalize from data on temporary mood state to more stable syndromes or disorders; and (d) attend to whether their concerns are primarily diagnostic (leading to differentiation among disorders, traits and states) or descriptive of particular disorders, traits and states in ways that might also apply to others.

\section{Remembered and Hypothetical Emotional States}

In some research there is no attempt to incorporate ongoing emotional states at all. Instead, the research relies on participants' memories of past emotional states, or on their intuitions about the nature of emotional reactions to scenarios that are depicted via text or film. There are various reasons for adopting such methods. For some research, actual emotional states are beside the point; for example, research on conceptions of emotion and on emotion knowledge quite properly addresses participants' conceptions rather than their emotions. In other cases the choice of remembered or imagined emotions is one of necessity or 
convenience rather than of preference. In research on appraisal, for example, most research has emphasized recollections or intuitions, not because real-time appraisals are not of interest but because these cognitive events are fleeting and subtle and thus difficult to capture with existing methods. Such research has been subject to various criticisms. Recollections may be more prone to schematic distortion than ongoing events, and imagined vignettes may lack the immediacy, personal importance, and gradual temporal development of real-life events (Levine, 1996; Parkinson \& Manstead, 1993).

One way to overcome some of these criticisms is to sample memories of emotions that are very recent, such as by scheduling frequent visits to the laboratory to report on recent emotional experiences (Sonnemans \& Frijda, 1995). In fact, the distinction between naturally occurring emotional states and remembered emotional states blurs as the interval between the end of the emotional state and collection of data shortens. The questionnaire and diary methods described in the section on naturally occurring emotions may well be more properly considered to be studies of remembered emotional states than of ongoing naturally produced ones.

Another way to blunt these criticisms is to ensure that participants recall or imagine the emotional state in such detail as to re-experience it prior to answering questions about it. This procedure may help to overcome the tendency toward schematic recall (Parrott \& Smith, 1991). Interestingly, it may work by actually reinstating (or inducing) an emotional state to some extent. It should be recalled that autobiographical memory is sometimes used as a mood induction, and that there is evidence that asking participants to re-experience a remembered emotional event makes the reinstated emotion more intense (Lantermann \& Otto, 1996). Procedures employing remembered or hypothetical emotional states may, therefore, actually induce real emotional states, at least under some circumstances. Nevertheless, the limitations of memory and intuition cannot be eliminated completely and, ideally, other methods should be used to complement them.

\section{MEASURING EMOTIONAL STATES}

Research that incorporates emotional states into the design requires that the quality and intensity of the emotional state be assessed in some way. The issues surrounding the measurement of emotional states are often complex and technical; all but the most basic overview is beyond the scope of this chapter. We try to supply that overview below, and include references that will guide the interested reader to more complete discussions. Our presentation is organized according to the three aspects of emotion that are commonly measured: self-report, behavior and physiology. It is important to note that these aspects are not components of a coherent emotion construct and correlate only imperfectly. They are often conceptualized as being separate processing levels or response systems that are not closely linked (Lang, 1988; Leventhal \& Scherer, 1987). 


\section{Self-report}

If one begins with the belief that emotional states are conscious, the primary way to assess their presence is self-report. But not all researchers believe that emotional states need be conscious, and even those that do usually also believe that there are interesting concomitants of these conscious states that occur outside of awareness (Ekman \& Davidson, 1994). Thus, for most researchers, self-reports of emotional states tap an important aspect of emotion, but not the only one. Selfreport is recommended when a person's conscious experience of emotional states is what needs to be assessed. An obvious advantage of self-report is that it is simple and convenient to use.

The assessment of conscious states can be problematic, however. There is little consensus about how conscious states arise; contemporary working hypotheses include direct causation by neural activity, perception-like inferences based on behavior or physiology, and perception of emotional meaning in objects and events (Parrott, 1995). All of these admit to a variety of distortions and biases due to expectations, social norms, attributions, allocation of attention and the like, and researchers must be mindful of these influences. Certainly, when an actual emotional state is not present at the time of selfreport these influences would seem likely to be especially threatening (Parkinson \& Manstead, 1993; Smith \& Lazarus, 1993). One recent study found some cause for reassurance by demonstrating that, although self-reports of hedonic tone may be influenced by the social desirability of the state, such bias cannot adequately account for the pattern of responses (Barrett, 1996). One possible disadvantage of self-report is that participants in research may infer that their emotional states are of interest to the researcher, which may lead to self-consciousness that may alter behavior. If this possibility is deemed a problem, solutions include disguising the self-report items by embedding them in another questionnaire, delaying measurement of emotional state until other critical variables are assessed, or assessing emotion with a method other than self-report.

For whatever reasons, self-report is overwhelmingly the most common method of measuring emotional states. The most common technique is the administration of a series of Likert or analog rating scales, although other formats may be used (e.g. Eich, 1995). These measures are often devised especially for each study, but it is also common to administer a published standardized inventory of ratings scales or a checklist. Among the most commonly used are the Positive and Negative Affect Scale (Watson, Clark \& Tellegen, 1988), the Discrete Emotions Scale (Izard, 1972), the Multiple Affective Adjective Checklist-Revised (Zuckerman \& Lublin, 1985), and the Spielberger State-Trait Anxiety Inventory (Spielberger et al., 1983). Different methods of scoring such measures introduce different forms of bias, and these must be taken into account when planning research (Green, Goldman \& Salovey, 1993). 


\section{Behavioral and Cognitive Indices}

An alternative means of measuring emotional states is to detect behavioral and cognitive patterns that are associated with them. The most common behavior used in research on cognition and emotion is the psychomotor retardation associated with sadness. Psychomotor retardation can be indexed via writing speed (Clark, 1983) or letter cancellation (Mayer \& Bremer, 1985). Other emotional states are associated with discrete behaviors, such as gaze aversion and blushing in the case of embarrassment (Asendorpf, 1990), and these can be very useful in detecting elements of emotional states not accessible to consciousness, as well as in detecting emotional states without making participants aware of researchers' interest in these states.

Facial expressions are one type of behavior often associated with emotional states. Research suggests that their occurrence is sensitive to the presence of actual or imagined social contexts, but when these are of interest or are controlled for, facial expressions may have some use as evidence for the presence and intensity of certain emotions (Ekman, Friesen \& Ancoli, 1980; Keltner \& Ekman, 1996).

The cognitive aspects of emotion that are the topic of much of this volume are understood well enough to be used as measures of emotion. Although it has been rare to date, alterations in attention, memory or judgment could serve as an index of particular emotional states, just as psychomotor retardation has been. When such tasks have been used as indexes of mood they have proven as effective as behavioral tasks (Kuykendall, Keating \& Wagaman, 1988; Mayer \& Bremer, 1985).

\section{Psychophysiological Indices}

Measurements of the physiological concomitants of emotional states may be used for all the reasons cited in favor of behavioral and cognitive indices. Researchers have creatively employed such measures to avoid the drawbacks of self-report measures, as when Pecchinenda \& Smith (1996) used measures of skin conductance activity to supplement possibly untrustworthy verbal reports of appraisal.

A variety of psychophysiological measures are commonly employed. They include heart rate, blood pressure, skin conductance, finger temperature, respiration and eye movement variability. Description of these methods is beyond the scope of this article, and readers are referred to such standard references as Cacioppo \& Petty (1983) and Wagner \& Manstead (1989). An interesting combination of psychophysiological and behavioral methods is employed when electromyographic (EMG) methods are used to detect activity of the muscles responsible for emotional facial expressions (Fridlund \& Cacioppo, 1986). EMG signals can be detected for movements too slight to be visible on the face, and the 
combined activity of different facial muscles can discriminate among emotions (Sinha \& Parsons, 1996).

More generally, as cognitive psychology moves in a neuroscience direction, interactions of cognition and emotion are increasingly assessed with neuropsychological techniques. For example, Henriques \& Davidson (1991) have linked depression-related difficulties in sustained attention to hypoactivation in the prefrontal cortex via EEG recordings. Dynamic neuroimaging techniques offer great promise as well, as illustrated by evidence from positron emission tomography suggesting changes in blood flow to various brain areas during emotional and non-emotional states (Drevets \& Raichle, in press). It is important to be aware that evidence concerning where in the brain such convergence occurs is correlational evidence, and therefore the usual warnings about causal inference apply (Sarter, Berntson \& Cacioppo, 1996).

\section{GENERAL ISSUES AND CONCLUSION}

\section{Control Conditions}

In designing experiments on cognition and emotion, the selection of appropriate control conditions is frequently necessary for two aspects of the experiment: first, if emotional state is an independent variable, there will usually need to be a control condition that establishes some sort of emotional baseline; and, second, if emotional stimulus materials are presented there will usually need to be materials that serve a non-emotional control. The selection of either type of control is less clear-cut than is often appreciated.

When emotional state serves as an independent variable, it is desirable to include a non-emotional control condition to clarify whether observed differences between emotional states are due to the effects of both states or only to those of one. For example, an experiment that compares the effects of elation to that of sadness will be unable to determine whether differences are due to changes caused by elation, by sadness or by both. If a non-emotional control condition is included, the two emotional conditions can be compared with it. The additional condition requires additional participants, and may have the effect of requiring smaller standard errors to detect a significant difference, but the benefits are often worth these costs.

The question that arises is how to construct the control. What is the proper control: no emotion at all? A random sample of everyday emotions? A random sample of everyday emotions that have been "toned down" so that there are no intense emotions? These conceptions imply different techniques and procedures. Some researchers do indeed try to eliminate emotional states in any participants experiencing them at the onset of the experiment. The opposite approach is to do nothing at all to the participants in the control condition and have them completely bypass the mood induction portion of the procedure. An intermediate 
approach is to provide control participants with an activity similar to that of the mood induction, but without the mood-altering qualities.

The three approaches are best clarified with an example. A study that uses comedy and tragedy films to induce happy and sad moods might attempt the first control strategy by showing a film that has a calming effect; the second control strategy would entail showing no film at all; and the third strategy would entail showing a brief film on a non-emotional subject, but only for the purpose of providing a film-watching experience, not with any attempt at altering the participants' emotional states. In general, the second strategy of bypassing the induction will have the problem of confounding emotional state with unknown effects of participating in film-watching, and is therefore usually not the best choice if only one control condition is to be used but can be informative in conjunction with other control conditions. The first strategy of inducing a "neutral" mood is conceptually problematic because of a lack of agreement about whether such a state exists, but the procedures may nevertheless have the effect of reducing the average intensity and thereby decreasing variability within the control group. The third strategy accepts a diverse sample of emotional states as the proper control, but probably alters them somewhat by imposing the task of watching a film. Either of these latter two controls has something to recommend it.

When an experiment exposes participants to emotional stimulus materials, another problem of control arises. Most frequently the problem arises when verbal materials are used, but pictures or photographs invite similar concerns (e.g. research on memory for central vs. peripheral details in emotional vs. nonemotional slides; see Heuer \& Reisberg, 1992). As an illustration, consider any finding of differential memory for materials that vary according to valence. Are emotional materials perceived or remembered better because they are emotional or because they differ in a number of characteristics from typically chosen neutral materials? The problem is obviously one of not being able to control, concomitantly, all the non-emotional characteristics of the materials. If we select within certain ranges of word frequency, length, linguistic function and concreteness, for example, we might find that the neutral words are more unrelated to one another than are the emotional words. Some researchers have approached this problem by using categorized neutral words, such as musical instruments or household items (Dalgleish, 1995; Mogg et al., 1991), but perhaps there are process-specific differences between these kinds of categorical relations and relations among words that are organized primarily in terms of the emotions they denote or evoke. "Materials effects", therefore, are difficult to interpret, although they tend to be suspected primarily when they are revealed as main effects (e.g. Hertel \& Milan, 1994). Moreover, they are suspected typically in experiments that use lists of words, instead of more ecologically valid scenes or descriptions, where they also might arise. Word-list experiments, however, typify mainstream cognitive paradigms, not because researchers lack imagination or concern with ecological validity, but because some measures of cognition require multi-trial formats and because characteristics of words have been normed. In short, problems arising from the use of emotionally valenced materials cannot be avoided merely by 
eschewing word lists. When the emotionality of the event is central to the issue under investigation, the researcher should consider explicitly the possibility that other co-varying characteristics of the event contribute to the outcome. This prescription is equally applicable to the study of naturally occurring events.

\section{Ecological Validity}

The challenge of ecological validity, increasingly raised by cognitive researchers more generally (Herrmann et al., 1996), is particularly sharp when events are infused with emotion, due to the methodological and ethical difficulties inherent in simulating emotional meaning or arousal in the laboratory (see Yuille \& Tollestrup, 1992). These difficulties have encouraged research paradigms that abandon traditional goals of experimental control. For example, assessments of autobiographical memories compounds the problems of lack of appropriate "materials" control with other potential confounds (e.g. practice in retrieval). When alternative explanations are thoroughly acknowledged or addressed, however, the study of autobiographical memory in emotional states or disorders reveals phenomena previously ignored or even obscured by traditional methods, such as the tendency of depressed people to produce overly general memories (Williams, 1992), or the phenomenon of mood-incongruent recall (Parrott \& Sabini, 1990). As a result, several researchers have advocated the two-pronged approach of complementary laboratory and naturalistic studies (e.g. Kihlstrom, 1996; Williams, 1992), and we concur. Few research programs to date actually incorporate both techniques, however. Although this research strategy has difficulty in addressing the issue of the causal status of the emotional valence of events, it does invite generality through diverse operational definitions of emotional value.

\section{Conclusion}

The issue of ecological validity in research on cognition and emotion is reminiscent of the debate about laboratory vs. "real-world" approaches to the study of memory (see Banaji \& Crowder, 1989, and the replies following Loftus, 1991). The themes that emerged from that debate stress the advantages of multiple methods for investigations of memory. The value of conducting memory research in everyday settings is not only that it builds confidence in the external validity of laboratory findings, but also that it permits study of important phenomena that are difficult to produce or to address under more controlled conditions. Our survey of research methods suggests that the same point holds true for research on cognition and emotion. While adhering to the values of controlled experimentation, we have emphasized the advantages to naturalistic investigation of cognition and emotion, and suggested that there is a natural complementarity between the two styles of research. 
As the field of cognition and emotion matures, there is a more general need for a two-pronged approach combining laboratory and more naturalistic studies. This recommendation emerges from the difficulties associated with the use of any one method alone. For example, the causal status of emotional states can best be established by experimental inductions of mood, but to gain this advantage one must pay the price of concern about demand characteristics, contextual priming and generalizability to natural states. Those costs can often be reduced through recruiting participants who experience such states "naturally" or by studying emotions produced under natural conditions. But these states may be accompanied by other characteristics that affect performance. The obvious solution is to use both methods - to manipulate and to measure emotional differences-while taking pains to acknowledge the methodological challenges of each method and to base conclusions on the consistencies or inconsistencies in the patterns obtained. Such comparisons can be made across studies rather than within if other aspects of the methods are similar, but they should be made.

With a few exceptions, however, this approach has been taken haphazardly or reconstructed in hindsight by writers of literature reviews. Greater systematic combination of multiple methods in laboratory and real-world settings would be a notable advance in the research methods in cognition and emotion. Such advances are necessary to continue the progress in understanding the causes and consequences of emotion from a cognitive perspective.

\section{REFERENCES}

Alloy, L. B., Kelly, K. A., Mineka, S. \& Clements, C. M. (1990). Comorbidity in anxiety and depressive disorders: a helplessness/hopelessness perspective. In J. D. Maser \& C. R. Cloninger (eds), Comorbitity in Anxiety and Mood Disorders. Washington, DC: American Psychiatric Press, pp. 499-543.

Asendorpf, J. (1990). The expression of shyness and embarrassment. In W. R. Crozier (ed.), Shyness and Embarrassment: Perspectives from Social Psychology. Cambridge: Cambridge University Press, pp. 87-118.

Banaji, M. R. \& Crowder, R. G. (1989). The bankruptcy of everyday memory. American Psychologist, 44, 1185-1193.

Barrett, L. F. (1996). Hedonic tone, perceived arousal, and item desirability: three components of self-reported mood. Cognition and Emotion, 10, 47-68.

Beck, A. T., Ward, C., Mendelson, M., Mock, J. \& Erbaugh, J. (1961). An inventory for measuring depression. Archives of General Psychiatry, 4, 561-571.

Berkowitz, L. \& Tróccoli, T. (1986). An examination of the assumption in the demand characteristics thesis: with special reference to the Velten mood induction procedure. Motivation and Emotion, 10, 337-349.

Blaney, P. H. (1986). Affect and memory: a review. Psychological Bulletin, 99, 229-246.

Bower, G. H. (1981). Mood and memory. American Psychologist, 36, 129-148.

Burt, D. B., Zembar, M. J. \& Niederehe, G. (1995). Depression and memory impairment: a meta-analysis of the association, its pattern, and specificity. Psychological Bulletin, 117, 285-305.

Byrne, A. \& Eysenck, M. W. (1995). Trait anxiety, anxious mood, and threat detection. Cognition and Emotion, 9, 549-562. 
Cacioppo, J. T. \& Petty, R. E. (1983). Social Psychophysiology: A Sourcebook. New York: Guilford.

Chartier, G. M. \& Ranieri, D. J. (1989). Comparison of two mood induction procedures. Cognitive Therapy and Research, 13, 275-282.

Clark, D. M. (1983). On induction of depressed mood in the laboratory: evaluation and comparison of the Velten and musical procedures. Advances in Behavior Research and Therapy, 5, 27-49.

Clark, L. A. \& Watson, D. (1991). Tripartite model of anxiety and depression: psychometric evidence and taxonomic implications. Journal of Abnormal Psychology, 100, 316-336.

Conway, M. A., Anderson, S. J., Larsen, S. F., Donnelly, C. M., McDaniel, M. A., McClelland, A. G. R., Rawles, R. E. \& Logie, R. H. (1994). The formation of flashbulb memories. Memory \& Cognition, 22, 326-343.

Cook, T. D. \& Campbell, D. T. (1979). Quasi-experimentation: Design and Analysis Issues for Field Settings. Boston, MA: Houghton Mifflin.

Dalgleish, T. (1995). Performance on the emotional stroop task in groups of anxious, expert, and control subjects: a comparison of computer and card presentation formats. Cognition and Emotion, 9, 341-362.

Deardorff, W. W. \& Funabiki, D. (1985). A diagnostic caution in screening for depressed college students. Cognitive Therapy and Research, 9, 277-284.

Drevets, W. C. \& Raichle, M. E. (in press). Reciprocal suppression of regional cerebral blood flow during emotional versus higher cognitive processes: implications for interactions between emotion and cognition. Cognition and Emotion.

Ehrlichmann, H. \& Halpern, J. N. (1988). Affect and memory: effects of pleasant and unpleasant odors on retrieval of happy and unhappy memories. Journal of Personality and Social Psychology, 55, 769-779.

Eich, E. (1995). Searching for mood-dependent memory. Psychological Science, 6, $67-75$.

Ekman, P. \& Davidson, R. J. (eds) (1994). The Nature of Emotion: Fundamental Questions. New York: Oxford University Press.

Ekman, P., Friesen, W. V. \& Ancoli, S. (1980). Facial signs of emotional experience. Journal of Personality and Social Psychology, 39, 1125-1134.

Ellis, H. C. \& Ashbrook, P. W. (1988). Resource allocation model of the effects of depressed mood states on memory. In K. Fiedler \& J. Forgas (eds), Affect, Cognition and Social Behavior. Toronto: Hogrefe, pp. 25-43.

Feist, G. J. (1994). The affective consequences of artistic and scientific problem solving. Cognition and Emotion, 8, 489-502.

Forgas, J. P. \& Moylan, S. (1987). After the movies: transient mood and social judgments. Personality and Social Psychology Bulletin, 13, 467-477.

Fox, E. (1996). Selective processing of threatening words in anxiety: the role of awareness. Cognition and Emotion, 10, 449-480.

Fridlund, A. J. \& Cacioppo, J. T. (1986). Guidelines for human electromyographic research. Psychophysiology, 23, 567-589.

Friswell, R. \& McConkey, K. M. (1989). Hypnotically induced mood. Cognition and Emotion, 3, 1-26.

Goodwin, A. M. \& Williams, J. M. G. (1982). Mood-induction research-its implications for clinical depression. Behavior Research and Therapy, 20, 373-382.

Gotlib, I. H. (1984). Depression and general psychopathology in university students. Journal of Abnormal Psychology, 93, 19-30.

Gotlib, I. H., Roberts, J. E. \& Gilboa, E. (1996). Cognitive interference in depression. In I. G. Sarason, G. R. Pierce \& B. R. Sarason (eds), Cognitive Interference: Theories, Methods, and Findings. Mahwah, NJ: Erlbaum, pp. 347-377.

Green, D. P., Goldman, S. L. \& Salovey, P. (1993). Measurement error masks bipolarity in affect ratings. Journal of Personality and Social Psychology, 64, 1029-1041. 
Gross, J. J. \& Levenson, R. W. (1995). Emotion elicitation using films. Cognition and Emotion, 9, 87-108.

Haaga, D. A. F. \& Solomon, A. (1993). Impact of Kendall, Hollon, Beck, Hammen, and Ingram (1987) on treatment of the continuity issue in "depression" research. Cognitive Therapy and Research, 17, 313-324.

Henriques, J. B. \& Davidson, R. J. (1991). Left frontal hypoactivation in depression. Journal of Abnormal Psychology, 100, 535-545.

Herrmann, D., McEvoy, C., Hertzog, C., Hertel, P. \& Johnson, M. K. (1996). Basic and Applied Memory Research: Theory in Context. Mahwah, NJ: Erlbaum.

Hertel, P. T. (1997). On the contributions of deficient cognitive control to memory impairments in depression. Cognition and Emotion, 11, 569-583.

Hertel, P. T. \& Milan, S. (1994). Depressive deficits in recognition: dissociation of recollection and familiarity. Journal of Abnormal Psychology, 103, 736-742.

Hertel, P. T. \& Rude, S. R. (1991). Recalling in a state of natural or induced depression. Cognitive Therapy and Research, 15, 103-127.

Heuer, F. \& Reisberg, D. (1992). Emotion, arousal, and memory for detail. In S. Christianson (ed.), The Handbook of Emotion and Memory. Hillsdale, NJ: Erlbaum, pp. 151-180.

Ingram, R. E. (1984). Toward an information processing analysis of depression. Cognitive Therapy and Research, 8, 443-478.

Isen, A. M., Shalker, T. E., Clark, M. \& Karp, L. (1978). Affect, accessibility of material in memory, and behavior: a cognitive loop? Journal of Personality and Social Psychology, 36, 1-12.

Izard, C. E. (1972). Patterns of Emotions: A New Analysis of Anxiety and Depression. New York: Academic Press.

Keltner, D. \& Ekman, P. (1996). Affective intensity and emotional responses. Cognition and Emotion, 10, 323-328.

Kendall, P. C., Hollon, S. D., Beck, A. T., Hammen, C. L. \& Ingram, R. E. (1987). Issues and recommendations regarding use of the Beck Depression Inventory. Cognitive Therapy and Research, 11, 289-299.

Kenealy, P. (1988). Validation of a music mood induction procedure: some preliminary findings. Cognition and Emotion, 2, 41-48.

Kihlstrom, J. F. (1996). Memory research: the convergence of theory and practice. In D. Herrmann, C. McEvoy, C. Hertzog, P. Hertel \& M. K. Johnson (eds), Basic and Applied Memory Research: Theory in Context. Mahwah, NJ: Erlbaum, pp. 5-25.

Kulik, J. A. \& Brown, R. (1979). Frustration, attribution of blame, and aggression. Journal of Experimental Social Psychology, 15, 183-194.

Kuykendall, D., Keating, J. P. \& Wagaman, J. (1988). Assessing affective states: a new methodology for some old problems. Cognitive Therapy and Research, 12, 279-294.

Laird, J. D., Cuniff, M., Sheehan, K., Shulman, D. \& Strum, G. (1991). Emotion specific effects of facial expressions on memory for life events. In D. Kuiken (ed.), Mood and Memory: Theory, Research, and Applications. Newbury Park, CA: Sage, pp. 87-98.

Lang, P. J. (1988). What are the data of emotion. In V. Hamilton, G. H. Bower \& N. Frijda (eds), Cognitive Perspectives on Emotion and Motivation, NATO ASI, Series D, Vol. 44. Dordrecht: Kluwer, pp. 173-191.

Lanterman, E. D. \& Otto, J. H. (1996). Correction of effects of memory valence and emotionality on content and style of judgments. Cognition and Emotion, 10, 505-527.

Larsen, R. J., Kasimatis, M. \& Frey, K. (1992). Facilitating the furrowed brow: an unobtrusive test of the facial feedback hypothesis applied to unpleasant affect. Cognition and Emotion, 6, 321-338.

Leventhal, H. \& Scherer, K. (1987). The relationship of emotion to cognition: a functional approach to a semantic controversy. Cognition and Emotion, 1, 3-28.

Levine, L. J. (1996). The anatomy of disappointment: a naturalistic test of appraisal models of sadness, anger, and hope. Cognition and Emotion, 10, 337-359. 
Loftus, E. F. (1991). The glitter of everyday memory ... and the gold. American Psychologist, 46, 16-18.

Magai, C., Distel, N. \& Liker, R. (1995). Emotion socialisation, attachment, and patterns of adult emotional traits. Cognition and Emotion, 9, 461-481.

Mayer, J. D., Allen, J. P. \& Beauregard, K. (1995). Mood inductions for four specific moods: a procedure employing guided imagery vignettes with music. Journal of Mental Imagery, 19, 133-150.

Mayer, J. D. \& Bremer, D. (1985). Assessing mood with affect-sensitive tasks. Journal of Personality Assessment, 49, 95-99.

Miller, G. A., Levin, D. N., Kozak, M. J., Cook, E. W. III, McLean, J. A. \& Lang, P. J. (1987). Individual differences in imagery and the psychophysiology of emotion. Cognition and Emotion, 1, 367-390.

Mogg, K., Mathews, A., May, J., Grove, M., Eysenck, M. \& Weinman, J. (1991). Assessment of cognitive bias in anxiety and depression using a colour perception task. Cognition and Emotion, 5, 221-238.

Nolen-Hoeksema, S. \& Morrow, J. (1991). A prospective study of depression and distress following a natural disaster: the 1989 Loma Prieta earthquake. Journal of Personality and Social Psychology, 61, 105-121.

Nolen-Hoeksema, S. \& Morrow, J. (1993). Effects of rumination and distraction on naturally occurring depressed mood. Cognition and Emotion, 7, 561-570.

Oatley, K. \& Duncan, E. (1994). The experience of emotions in everyday life. Cognition and Emotion, 9, 369-381.

Overwalle, F. Van, Mervielde, I. \& De Schuyter, J. (1995). Structural modelling of the relationships between attributional dimensions, emotions, and performance of college freshmen. Cognition and Emotion, 9, 59-85.

Parkinson, B. \& Manstead, A. S. R. (1993). Making sense of emotion in stories and social life. Cognition and Emotion, 7, 295-323.

Parrott, W. G. (1991). Mood induction and instructions to sustain moods: a test of the subject compliance hypothesis of mood congruent memory. Cognition and Emotion, $\mathbf{5}$, 41-52.

Parrott, W. G. (1993). Beyond hedonism: motives for inhibiting good moods and for maintaining bad moods. In D. M. Wegner \& J. W. Pennebaker (eds), Handbook of Mental Control. Englewood Cliffs, NJ: Prentice-Hall, pp. 278-305.

Parrott, W. G. (1995). Emotional experience. In A. S. R. Manstead \& M. Hewstone (eds), The Blackwell Encyclopedia of Social Psychology. Oxford: Basil Blackwell, pp. 198-203.

Parrott, W. G. \& Sabini, J. (1990). Mood and memory under natural conditions: evidence for mood incongruent recall. Journal of Personality and Social Psychology, 59, 321-336.

Parrott, W. G. \& Smith, S. F. (1991). Embarrassment: actual vs. typical cases, classical vs. prototypical representations. Cognition and Emotion, 5, 467-488.

Pecchinenda, A. \& Smith, C. A. (1996). The affective significance of skin conductance activity during a difficult problem-solving task. Cognition and Emotion, 10, 481503.

Perrig, W. J. \& Perrig, P. (1988). Mood and memory: mood-congruity effects in absence of mood. Memory \& Cognition, 16, 102-109.

Philippot, P. (1993). Inducing and assessing differentiated emotion-feeling states in the laboratory. Cognition and Emotion, 7, 171-193.

Planalp, S., DeFrancisco, V. L. \& Rutherford, D. (1996). Varieties of cues to emotion in naturally occurring situations. Cognition and Emotion, 10, 137-153.

Rimé, B., Mesquita, B., Philippot, P. \& Boca, S. (1991). Beyond the emotional event: six studies on the social sharing of emotion. Cognition and Emotion, 5, 434-465.

Salovey, P. \& Rodin, J. (1984). Some antecedents and consequences of socialcomparison jealousy. Journal of Personality and Social Psychology, 47, 780-792. 
Sarter, M., Berntson, G. G. \& Cacioppo, J. T. (1996). Brain imaging and cognitive neuroscience. American Psychologist, 51, 13-21.

Schiff, B. B., Esses, V. M. \& Lamon, M. (1992). Unilateral facial contractions produce mood effects on social cognitive judgements. Cognition and Emotion, 6, 357-368.

Seibert, P. S. \& Ellis, H. C. (1991). A convenient self-referencing mood induction procedure. Bulletin of the Psychonomic Society, 29, 121-124.

Sinha, R. \& Parsons, O. A. (1996). Multivariate response patterning of fear and anger. Cognition and Emotion, 10, 173-198.

Slyker, J. P. \& McNally, R. J. (1991). Experimental induction of anxious and depressed moods: are Velten and musical procedures necessary? Cognitive Therapy and Research, $15,33-45$.

Smith, C. A. \& Lazarus, R. S. (1993). Appraisal components, core relational themes, and the emotions. Cognition and Emotion, 7, 233-269.

Snyder, M. \& White, P. (1982). Moods and memories: elation, depression, and the remembering of the events of one's life. Journal of Personality, 50, 149-167.

Sonnemans, J. \& Frijda, N. H. (1995). The determinants of subjective emotional intensity. Cognition and Emotion, 9, 483-506.

Spielberger, C. D., Gorsuch, R. L., Lushene, R., Vagg, P. R. \& Jacobs, G. A. (1983). Manual for the State-Trait Anxiety Inventory (Form Y). Palo Alto, CA: Consulting Psychologists Press.

Velten, E. (1968). A laboratory task for induction of mood states. Behavior Research and Therapy, 6, 473-482.

Vredenburg, K., Flett, G. L. \& Krames, L. (1993). Analogue versus clinical depression: a critical reappraisal. Psychological Bulletin, 113, 327-344.

Wagner, H. L. \& Manstead, A. (eds) (1989). Handbook of Social Psychophysiology. Chichester: Wiley.

Watson, D., Clark, L. A. \& Tellegen, A. (1988). Development and validation of brief measures of positive and negative affect: the PANAS scales. Journal of Personality and Social Psychology, 54, 1063-1070.

Williams, J. M. G. (1992). Autobiographical memory and emotional disorders. In S. Christianson (ed.), The Handbook of Emotion and Memory. Hillsdale, NJ: Erlbaum, pp. 451-477.

Williams, J. M. G., Watts, F. N., MacLeod, C. \& Mathews, A. (1988). Cognitive Psychology and Emotional Disorders. New York: Wiley.

Yuille, J. C. \& Tollestrup, P. A. (1992). A model of the diverse effects of emotion on eyewitness memory. In S. Christianson (ed.), The Handbook of Emotion and Memory. Hillsdale, NJ: Erlbaum, pp. 201-215.

Zuckerman, M. \& Lubin, B. (1985). Manual for the Multiple Affect Adjective ChecklistRevised. San Diego, CA: Edits. 